\title{
HAPEX-Sahel: a large-scale study of land-atmosphere interactions in the semi-arid tropics
}

\author{
J-P. Goutorbe ${ }^{1}$, T. Lebel ${ }^{2}$, A. Tinga ${ }^{3}$, P. Bessemoulin' ${ }^{1}$, J. Brouwer ${ }^{4}$, A.J. Dolman ${ }^{5,6}$, E.T. Engman7, J.H.C. Gash5, \\ M. Hoepfiner, ${ }^{8}$ P. Kabat ${ }^{6}$, Y.H. Kerr ${ }^{9}$, B. Monteny ${ }^{2}$, S. Prince ${ }^{10}$, F. Said ${ }^{11}$, P. Sellers', J.S. Wallace \\ ${ }^{1}$ CNRM, 42 Av. G. Coriolis, 31057, Toulouse, France \\ 2 ORSTOM. BP 11416, Niamey. Niger \\ ${ }^{3}$ Université de Niamey, Niamey, Niger \\ 4 ICRISAT, BP 12404, Niamey, Niger and Dept. Soil Science \& Geology. P.O. Box 37, 67(0) AA. Wageningen, The Netherlands \\ 5 Institute of Hydrology. Wallingford, OX10 8BB. UK \\ 6 Winand Staring Centre (SC-DL_O), P.O. Box 125, 6700 AC. Wageningen. The Netherlands \\ 7 NASA GSFC Greenbelt, MD 20771, USA \\ ${ }^{8}$ ORSTOM BP 5()45. F-34032 Montpellier. France \\ ${ }^{9}$ LERTS, 18 Av. E. Belin, 31055 Toulouse. France \\ 10 University of Maryland, College Park, MD 20742-8225, USA \\ 11 UPS Laboratoire d'Aerologic, 31062 Toulouse, France
}

Received 4 June 1993 / Revised: 4 October 1993 / Accepted: 11 October 1993

\begin{abstract}
The Hydrologic Atmospheric Pilot EXperiment in the Sahel (HAPEX-Sahel) was carried out in Niger, West Africa, during 1991-1992, with an intensive observation period (IOP) in August-October 1992. It aims at improving the parameterization of land surface atmosphere interactions at the Global Circulation Model (GCM) gridbox scale. The experiment combines remote sensing and ground based measurements with hydrological and meteorological modelling to develop aggregation techniques for use in large scale estimates of the hydrological and meteorological behaviour of large areas in the Sahel.

The experimental strategy consisted of a period of intensive measurements during the transition period of the rainy to the dry season, backed up by a series of long term measurements in a $1^{\circ}$ by $1^{\circ}$ square in Niger. Three "supersites" were instrumented with a variety of hydrological and (micro) meteorological equipment to provide detailed information on the surface energy exchange at the local scale. Boundary layer measurements and aircraft measurements were used to provide information at scales of $100-500 \mathrm{~km}^{2}$. All relevant remote sensing images were obtained for this period. This programme of measurements is now being analyzed and an extensive modelling programme is under way to aggregate the information at all scales up to the GCM grid box scale. The experimental strategy and some preliminary results of the IOP are described.
\end{abstract}

\section{Introduction}

GCMs used for climate change prediction are based on grids several hundred kilometres square. At each point on the grid the land surface energy, water and momentum balance needs to be calculated at each time step in the model. This must be achieved with what amounts to a single sub-model which must represent the complete grid square. Increased understanding of land-surface atmosphere interaction has led to these sub-models continually becoming more realistic. This creates a need for data and for measurement and modelling techniques which can be used to quantify the varied landscape likely to be contained within areas at the required scale. A series of large-scale international experiments have now been executed, (see Shuttleworth, 1991 for a review and discussion of these experiments in the context of various international programmes): for example HAPEX-MOBILHY in France (André et al., 1988), FIFE in the USA (Sellers et al., 1992), and EFEDA in Spain (Bolle et al., 1993). These have proved successful in developing the experimental strategies necessary to provide such data and the subsequent modelling efforts aimed at integrating all these data up to the GCM grid square scale (Bougeault $e t$ al., 1991, Noilhan and Lacarrère, 1993). HAPEX-Sahel is an experiment designed to fulfil the requirement for modelling the climate and hydrology of the semi-arid, sahelian, region of sub-Saharan Africa.

The Sahel comprises an area of some $3 \times 10^{6} \mathrm{~km}^{2}$ lying between the wet, humid, equatorial zone of Africa to the south, and the Sahara Desert to the north. This results in a strong north-south rainfall gradient and a climate with a notoriously unreliable rainfall. The rainfall is now generally accepted to have been declining for the past two decades (Nicholson, 1989), and attempts to understand this phenomenon have been one of most active areas of application 
for GCMs (Rowntree, 1988). Previous studies (e.g. Charney, 1975, Laval and Picon, 1986) have shown a sensitivity to albedo, with a reduction in rainfall resulting from the increased albedo associated with the removal of vegetation. Other studies (e.g., Folland et al.,; 1991) have indicated that external factors such as changes in Atlantic sea-surface temperature may also be responsible. Understanding the reasons for the decline in rainfall and the need to predict how the climate may change in the future - either in response to local vegetation change, or in response to external factors such as global $\mathrm{CO}_{2}$ increase - have provided the incentive for HAPEX-Sahel.

HAPEX-Sahel consists of 66 separate studies. Clearly in a single paper it is not possible to describe each of these studies in detail and no attempt will be made to do so. This paper describes the design of the experiment, in terms of the sampling strategy, the measurements taken and the modelling philosophy aimed at integrating local scale measurements up to the GCM grid square scale. A broad description of the experimental sites is given, together with some data to indicate the range of climatic conditions experienced during the intensive observation period (IOP).

\section{Methodology}

\section{2.l Experimental strategy}

The HAPEX-Sahel experiment attempts to bridge the gap between the local and the GCM grid box scale. The strategy developed to achieve this ambitious goal is based on a twostream approach, which draws heavily on experiences from previous large scale field experiments such as HAPEX- MOBILHY and FIFE. The two-stream approach is based on the integration of remote sensing and ground measurements, and hydrological and meteorological modelling. It aims to provide a full assessment of the potential of these techniques to produce large scale estimates of relevant land surface characteristics and surface energy, water, $\mathrm{CO}_{2}$ and momentum fluxes. The experimental design of HAPEX-Sahel reflects this philosophy (e.g. Goutorbe et al., 1992).

\subsection{The Sahelian environment}

The climate of continental west Africa is influenced by the interaction of the air masses over large homogeneous areas of sea and land. The two air maises meet in a zone which is often referred to as the intertropical convergence zone (ITCZ), the ascending branch of the Hadley cell. The tropical continental air mass containing warm, dry air and which is generally hazy, originates from the Sahara desert. It slopes upwards to the south over the warm, humid tropical maritime air originating over the Atlantic which forms a wedge under the continental air mass. The seasonal migration of the ITCZ is of fundamental importance in understanding the climate of West Africa.

The north-south migration of the ITCZ is related to the seasonal shifts in the relative positioning of the sun. During June and July, a large part of West Africa is under the influence of moist southwesterly air masses, giving rise to the rainy season. The maximum northward extent of the ITCZ is reached in August, when the maximum rainfall occurs in the Sahel. Depending on the depth of the humid air mass, thunderstorms with heavy rainfall can occur.

The Sahelian region comprises the semi-arid vegetation belt south of the Sahara desert and north of the dry forest zone. The duration of the wet season decreases from about 5 months in the south of the Sahel $\left(12^{\circ} \mathrm{N}\right)$ to 3 months in the north $\left(18^{\circ} \mathrm{N}\right)$. The annual rainfall is closely related to the duration of the rainy season, varying from $800 \mathrm{~mm}$ in the south to only $200 \mathrm{~mm}$ in the north, following a regular gradient of $1 \mathrm{~mm} \mathrm{~km}^{-1}$ (averages from 1950-1989; Lebel et al., 1992).

The highly variable and unreliable rainfall governs the growth and distribution of the vegetation. Total rainfall is everywhere less than potential evaporation, which is of the order of $2000 \mathrm{~mm}$ per year. This results in a highly sparse vegetation cover with large areas of bare soil. The interlacing of bare soil and vegetation creates a large variability of surface conditions at the $0.01-1 \mathrm{~km}^{2}$ scale. However, the somewhat uniform geological and pedological structures generate a relatively homogeneous regional landscape.

Another major aspect of the Sahelian environment is the marked degradation of drainage networks, as a result of highly intermittent streamflow characteristics. Sahclian hydrology is therefore primarily the hydrology of endoreic (inward draining) areas, the surface areas of which rarely exceed a few square kilometres. This results in the formation of ponds and pools in the beginning of the rainy season, which dry out 2-3 months after the last rainfall. The areas which drain externally do not behave as watersheds in the classical sense either: runoff rapidly dissipates as the șlopes become too weak. It is therefore generally impossible to rely on measured streamflow at the watershed outlet to provide spatially integrated values of the residual (evaporation) term in the water balance. The emphasis must thus be placed on meteorological techniques to obtain the (spatially) integrated evaporation.

\subsection{Spatial sampling and measurement strategy}

The experiment is based on a $1^{\circ} \times 1^{\circ}$ square $\left(2-3^{\circ} \mathrm{E}\right.$, $13-14^{\prime \prime} \mathrm{N}$ ). This area (approximately $100 \mathrm{~km} \times 100 \mathrm{~km}$ ) is comparable in size to a GCM grid square and large enough to contain a representative sample of the variability of Sahelian vegetation.

Three super-sites were selected for intensive monitoring. Their position, chosen to capture the expected long term climatological rainfall gradient, is shown in Fig. 1. The scale of the super-sites reflects the scale at which the atmospheric boundary layer responds to changes in the land surface (typically 10-20 km). This makes the super-sites sufficiently large for aircraft and boundary layer measurements, while at the same time they can be used for testing and developing remote sensing algorithms. Two less heavily instrumented sites were also established, one northwest of Niamey, at Danguey Gourou, and one east of Niamey, in the river valley the Dallol Bosso. These were to extend the spatial coverage over the square. In addition to these sites a network of automated weather stations was established over the full 


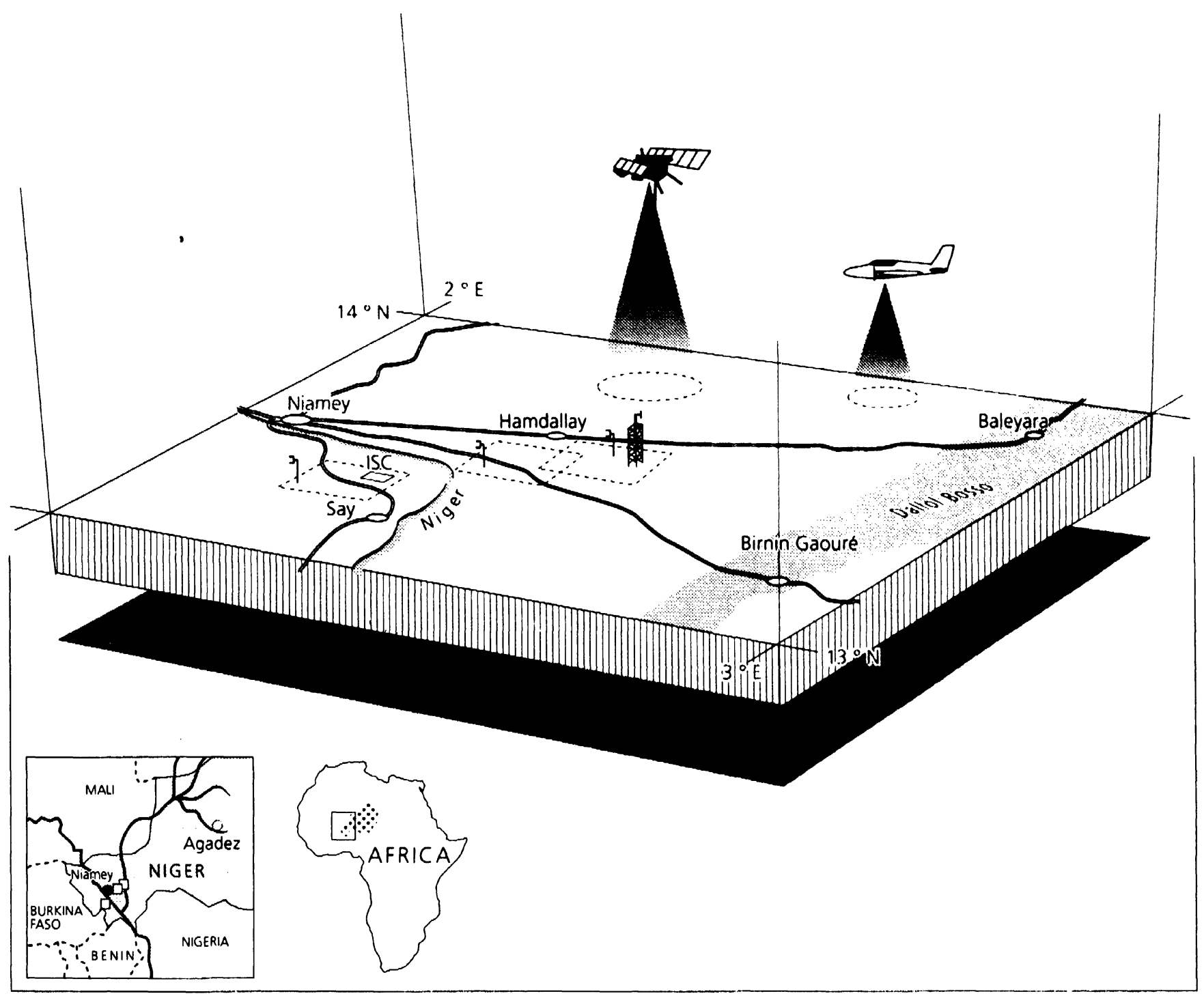

Fig. 1. Diagram showing the position of the experimental square and the three super-sites

$1^{\circ}$ by $1^{\circ}$ square giving information on the regional-scale variability of the main climatic variables.

At the super-site scale energy fluxes will be estimated using the data provided by eddy correlation instruments mounted on low-flying aircraft and through the study of the boundary layer development. On the ground, extensive micrometeorological measurements of energy and carbon fluxes, and vegetation, soil and hydrological measurements were performed at sub-sites. There was one sub-site for each of the main vegetation types. Within the sub-sites further studies looked at the variation in the energy balance resulting from the different components of the vegetation and bare soil.

The large differences in vegetation, rainfall, soil moisture conditions and hydraulic properties over the square require the use of upscaling techniques to obtain an area-integrated view of the hydrological processes operating in the $1^{\circ}$ by $1^{\circ}$ square. The vegetation within the square will be classified and mapped using a combination of ground-based, aircraft and satellite data; primary production has been monitored. The EPSAT-Niger experiment, which comprises a dense network of rain gauges in combination with weather radar data, will be used to obtain the spatial variability of rainfall input to the square. Stochastic and remote sensing techniques will then be used to integrate the local scale information on rainfall, soil moisture condition and hydraulic properties to the large scale, where they can be used as inputs to mesoscale models and GCMs. The long term input of water to the aquifer is to be estimated under a monitoring programme using existing wells and boreholes.

\subsection{Temporal sampling strategy}

The data collection took place over a period of 2 years, 1991-1993, with an IOP from 15 August to 9 October 1992. The IOP was timed to capture the transition from the wet to the dry season, in which both soil moisture and 
vegetation changes combine with changing meteorological conditions, to produce a radical transformation in the surface energy balance of the region (Gash et al., 1991). The 2-year data span allows investigation of hydrological processes operating on seasonal or longer time scales, such as soil moisture and runoff, while the relatively short IOP provides data for processes operating on smaller time scales such as the surface fluxes of heat and water vapour. During the IOP several aircraft were involved in both remote sensing and flux measurement missions.

\subsection{Aggregation}

Remote sensing techniques offer the opportunity to extrapolate local measurements to the larger scale. Within HAPEXSahel inverse modelling techniques will be used to obtain relevant land surface characteristics at pixel scales of, say $40 \mathrm{~m}^{2}$ to $2500 \mathrm{~km}^{2}$. Similar techniques using aircraft and satellite measurements of, for instance, reflectance patterns, surface temperature and soil moisture, will be used to reach the level of the GCM grid box scale. Essential in this attempt is the unique combination of ground truth data, covering a variety of vegetation, soil types and soil moisture patterns, with aircraft and satellite imagery, and atmospheric profile data for correcting satellite measurements. Ten years of Meteosat B2 data and 4 years of AVHRR data are available for this experiment.

However, interactions between the land surface characteristics and the surface fluxes of heat, water vapour and momentum are generally non-linear. Therefore, whilst remote sensing techniques can be used to provide information on the spatial variability of land surface characteristics such as albedo, aerodynamic roughness and soil moisture, meteorological modelling must also be used to investigate the interaction between adjacent areas having different surface characteristics. Mesoscale models have a typical domain size of a few hundred kilometres and a resolution of 5-25 km and have been successfully used in the past to investigate the effects of different land surface cover on the area-integrated surface fluxes (e.g., Bougeault et al., 1991). At the smaller scale, relevant to the "footprint" of the atmospheric boundary layer, two dimensional boundary layer (Blyth et al., 1993) and non-hydrostatic mesoscale models (Adrian and Fiedler, 1991) can be used to obtain area-integrated surface fluxes at the level of the super-site. Both these techniques will be used in HAPEX-Sahel so that the information which exists at the local and super-site scale can be integrated up to the GCM gridbox scale.

The unique combination of large, high quality datasets coupled with remote sensing techniques and modelling at a variety of spatial scales, both for hydrology and meteorology, should provide fascinating new insights in the large scale interaction of the land surface and the atmosphere in desertification threatened, semi-arid areas such as the $\mathrm{Sa}$ hel, and provide new and rigorous tests for aggregation algorithms.

\section{Site description and measurements}

In the following a detailed description of the area, vegetation, the sites and the measurements taken during the campaign will be given.

\section{I Description of the area}

A $1^{\circ}$ by $1^{\circ}$ square $\left(2-3^{\circ}\right.$ E, $\left.13-14^{\circ} \mathrm{N}\right)$ was chosen as a representative area of the Sahel. It is situated to the east of Niamey, the capital city of Niger, see Fig. 1. Figure 2 presents a composite image of the square, obtained from several Landsat overpasses, showing the variation in vegetation cover, together with the course of the river Niger. The $1^{\circ}$ by $1^{\circ}$ square was chosen for a number of reasons, amongst which the presence of long-term hydrological observations by ORSTOM (Lebel, 1990), the existence of a dense network of rain gages (the EPSAT-Niger project, Lebel et al., 1992) and previous micrometeorological studies (e.g., Gash et al., 1991, Durand et al., 1988, Frangi et al., 1992) were the most important. The physical geography of the area consists of the remains of the continental terminal, dissected into ferruginous plateaux separated by sand-filled valleys. The plateaux become less distinct towards the north. To the east, the square is bounded by an ancient river valley, the Dallol Bosso. The water table in the Dallol Bosso is nearly at the surface during the wet season, and 4-5 $\mathrm{m}$ below the surface in the dry season, giving the area its distinct, wet and lush character.

The vegetation within the HAPEX-Sahel square is typical of that occurring in the southern Sahelian zone. There are three main vegetation types, arable crops (almost ęntirely millet), fallow savannah and sparse dryland forest known locally as tiger bush. The areas of millet (Pennisetum glaucum (L.) R.Br.) are planted at the beginning of the rainy scason. The fallow savannah contains diverse mixtures of naturally occurring perennial woody shrubs and herbaceous annual plants. Throughout the square the dominant woody shrub in the fallow savannah is Guiera senegalensis (L.). The savannah areas will have been previously used for growing crops, but form part of a rotation system with a cycle which varies from a few years to up to 15 or 20 years. In recent times the shorter rotations have become more common. Tiger bush only occurs on the laterite plateaux. The tiger bush regetation is dominated by comparatively large woody perennials (e.g., Combretum micranthum G. Don) and trees (e.g., Combretum nigricans Lepr. ex Guill. and Perrott.). The vegetation grows in dense strips which are separated by areas of completcly bare soil. The proportion of vegetation cover within the tiger bush arcas varies according to the rainfall such that the densest cover is at the southern most part of the square and this decreases towards the north. The areas of tiger bush can be clearly seen in Fig. 2. Although the occurrence of laterite plateaux does not vary much with the north-south gradient, the amount of vegetation on them does. 


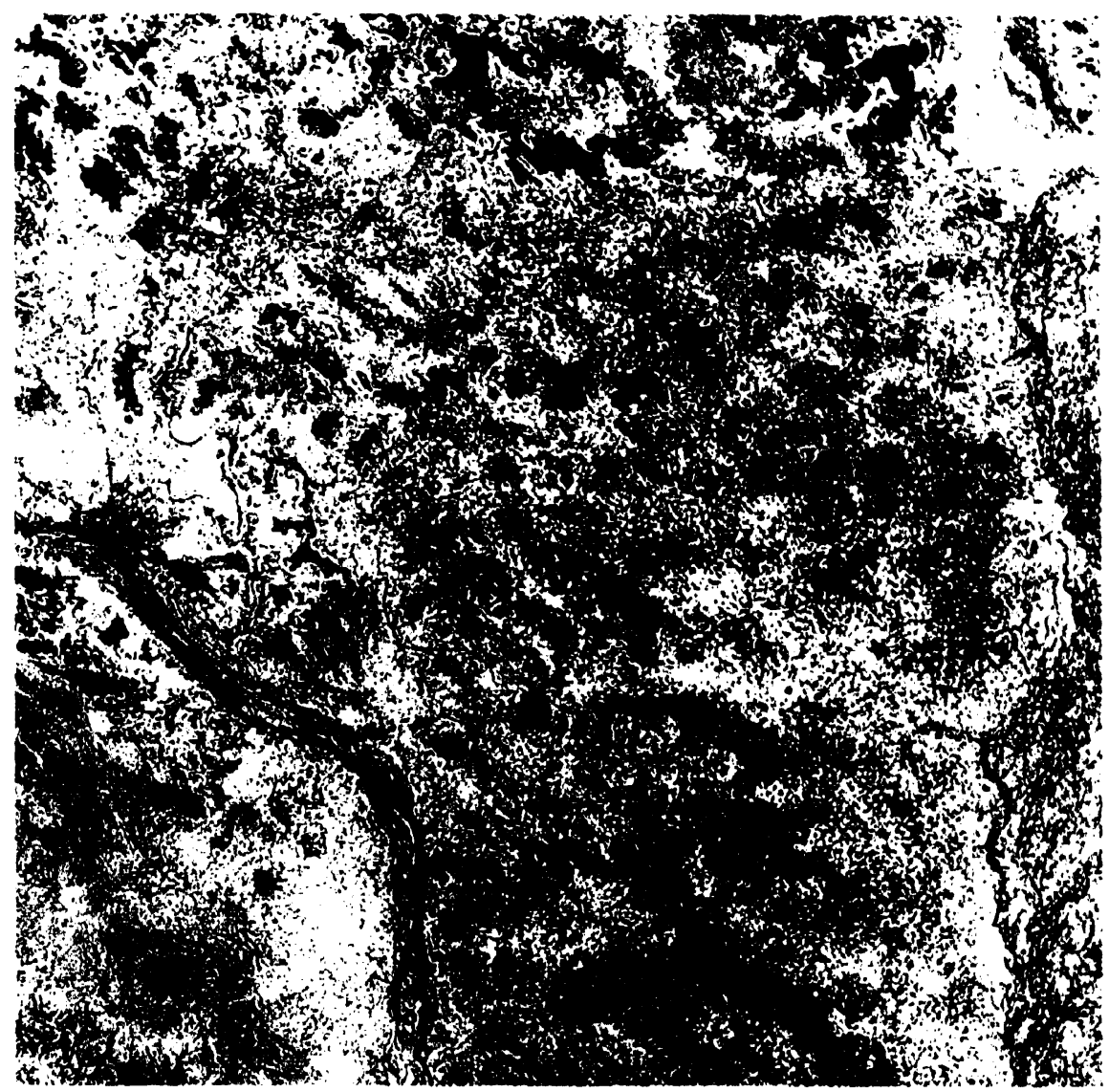

Fig. 2. Satellite image (LANDSAT) of the experimental area (image provided by the Institute of Hydrology. Wallingford. UK)

\subsection{Large scale spatial monitoring}

The monitoring of the entire experimental zone is designed to characterize the environment and its evolution and to study the large scale processes.

The first results of EPSAT-Niger (Taupin et al., 1993) have shown that the spatial variability of rainfall is very large at all time scales. They concluded that a density of roughly one gauge per $100 \mathrm{~km}^{2}$ was needed to estimate rainfall inputs over areas in excess of $500 \mathrm{~km}^{2}$. Areas smaller than $500 \mathrm{~km}^{2}$ required an increasing number of gauges with decreasing area. To capture the spatial variation in rainfall, a network of 107 recording gauges was installed on a $12 \mathrm{~km}$ square basic mesh, with additional gauges at the super-sites to capture the local variability. This network was operated in conjunction with a C-band weather radar system located at Niamey airport. The weather radar provided $500 \mathrm{~m}$ radial resolution at $1.5^{\circ}$ angular resolution.

Assessment of upper aquifer recharge requires a direct measurement of aquifer levels - because the aquifer in the area is not continuous and the recharge is a point process both in time (individual rainfall events) and space. Two hundred access points to the upper aquifer to the east of the river were monitored every 3 months and recording piezometers provided a continuous survey in time at six locations. On the western side of the river, 50 wells have been monitored monthly since 1991 .
Synoptic conditions were monitored during the IOP with a network of 12 automatic weather stations, evenly spread over the $\mathrm{I}^{\text {" by }} \mathrm{I}^{\circ}$ square.

The last component of the large scale monitoring refers to the role of the vegetation in controlling the water balance of the area. It aimed at mapping the surface conditions and land units, classifying the fallow land according to various types of vegetation cover and monitoring the phenology of the main types in the study area. The sites of the EPSAT-Niger network were used as sampling points for both the surface conditions and vegetation mapping and phenology monitoring. The fieldwork, which began in 1990 and consisted of a local characterisation of the vegetation and radiometric measurements on the ground, was used for calibration of SPOT imagery. It should be stressed that, with the exception of the synoptic network, all the large scale monitoring started in 1990/1991 and continued until 1993. This provides essential long term background data for the experiment.

\subsection{The super-sites}

The location of the southern super-site is shown in Fig. 1. The site was on the right bank of the river Niger about $45 \mathrm{~km}$ south of Niamey, close to the ICRISAT Sahelian Centre at Sadoré. There were three contrasting sub-sites: a millet site, a fallow site and a tiger bush site. The millet site consisted 
of four adjacent fields, in total about $400 \times 400 \mathrm{~m}$, under traditional agriculture with millet interspersed by occasional trees (about 3 per hectare) 4-8 $\mathrm{m}$ high. The fallow site was on land which had not been cropped for about six years, allowing the natural vegetation of shrubs interspersed with annual grasses and legumes, to regenerate. The area measured about $800 \times 1000 \mathrm{~m}$. The tiger bush site was in an area of this open, natural forest which is found on the plateaux and contains strips of dense vegetation and large areas of crusted, bare soil. The site was near the centre of an area of tiger bush about $3 \mathrm{~km}$ across (see Dolman et al., 1993 and Culf et al., 1993 for further details).

The location of the central-east super-site is also shown in Fig. 1. The site was about $65 \mathrm{~km}$ east of Niamey close to the village of Banizoumbou. The site was based around the catchment of an ephemeral stream, the Sama Dey. It contained four sub-sites: a millet field, a large savannah area, a sandy skirt, cropped with millet on the transition between the plateau and the valley, and a tiger bush sub-site on a large plateau. The millet field, located in the bottom of the valley, comprised an area of 7-8 hectares with a crop density of $6500-7000$ plants per hectare. The savannah area consisted mainly of Guiera senegalensis, which covered $20 \%$ of the ground. The tiger bush site on the plateau, which was chosen for a detailed water budget study, consisted of strips of vegetation interspersed with bare soil.

The location of the central-west super-site is also shown in Fig. 1. The site was about $15 \mathrm{~km}$ west of the central-east site, centred on the village of Fandou Beri. There were four sub-sites representing the major land cover types: millet, fallow savannah, a more degraded fallow savannah and tiger bush.

Limited measurements were also taken at small sites at Danguey Gourou and near the village of Gourmandey in the Dallol Bosso valley. These sites were chosen to capture a greater degree of the expected gradient in rainfall and vegetation in the square. At Danguey Gourou measurements were taken in an area of millet; at Gourmandey in an area of mixed millet and grazing land.

\section{Conditions during the IOP}

\subsection{Rainfall}

The timing of the IOP was intended to cover a period of rainfall at the end of the wet season, and the start of the subsequent drying out. The location of super-sites was intended to cover some of the range of rainfall which, on average, occurs across the square. Given the variability in rainfall in this region neither could be guaranteed. However the rainfall experienced in 1992 was not untypical. Figure 3 shows the rainfall recorded at Banizoumbou (central-east site) and Djokoti (southern site), Dangue Gourou, and the average for the $1^{\circ}$ by $1^{\circ}$ square for the whole of the 1992 wet season. The total rainfall measured at Banizoumbou was $410 \mathrm{~mm}$, and at Djokoti an exceptionally high $782 \mathrm{~mm}$. The rainfall at the southern site was close to average both in timing and amount. In contrast there was little rainfall at the central sites until the beginning of the IOP and the total rainfall during the wet season was one of the lowest of the

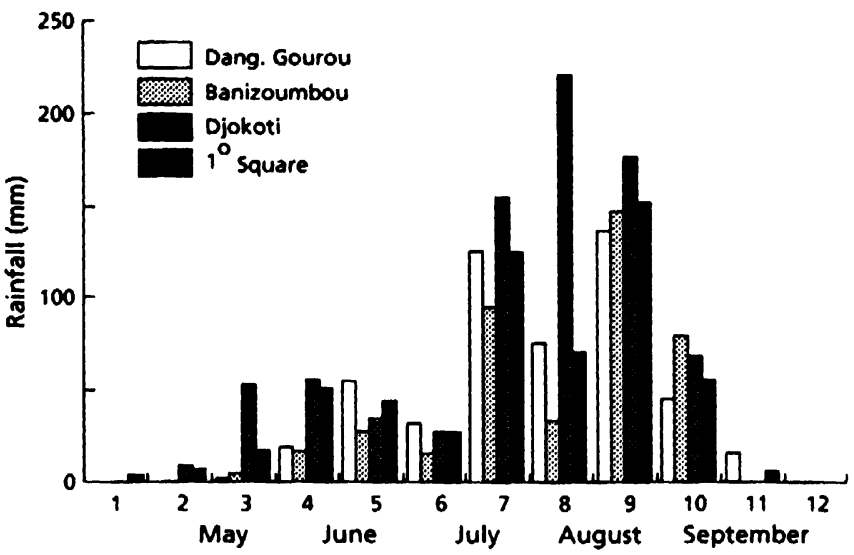

Fig. 3. The rainfall recorded at the Southern (Djokoti) and Central-East super-site (Banizoumbou) and Danguey Gourou and the average of the $1^{\circ}$ gridsquare for the whole of the 1992 wet season (data provided by EPSAT. Niger/ORSTOM)

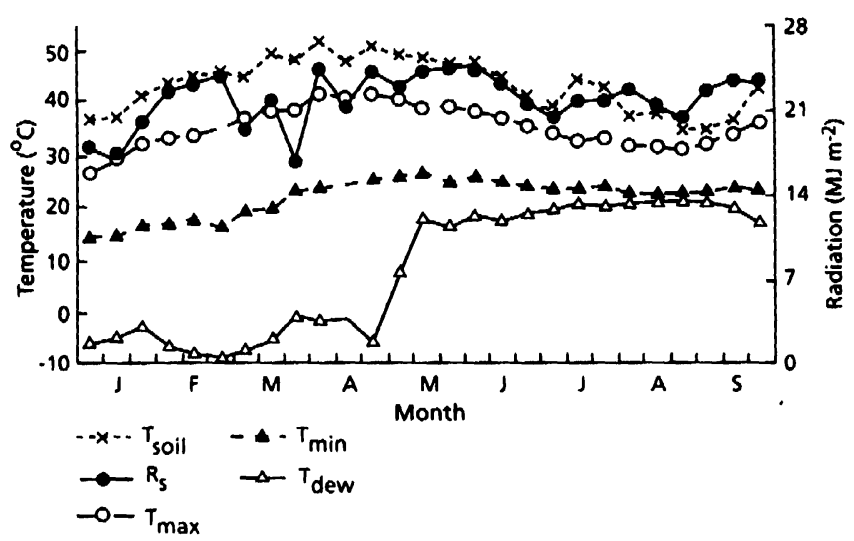

Fig. 5. Climate data for 1992 from the Banizoumbou site showing the seasonality of the Sahelian climate (data provided by ORSTOM, Niamey, Niger)

EPSAT-Niger study area. After 16 September there was no rain at any of the sites.

The strong observed differences in rainfall are consistent with those observed in 1990 and 1991 (Lebel et al., 1992). The strongest spatial gradient in rainfall was observed over the southern site with a maximum of $782 \mathrm{~mm}$ and a minimum of $507 \mathrm{~mm}$ over a distance of only $9 \mathrm{~km}$. Over the central sites the rainfall distribution was somewhat more homogeneous. An indication of the strong rainfall variability can be gained from Fig. 4 , where the areal rainfall is plotted for the total $1^{\circ}$ by $1^{\circ}$ square. The total estimated rainfall over the study area was close to average with a value of $537 \mathrm{~mm}$. This compares with a value of $550 \mathrm{~mm}$ estimated for the period 1950-1990. The 15-day average rainfall over the study area remained below $50 \mathrm{~mm}$ until the second 15-day period, indicating a late start to the rainy season. 


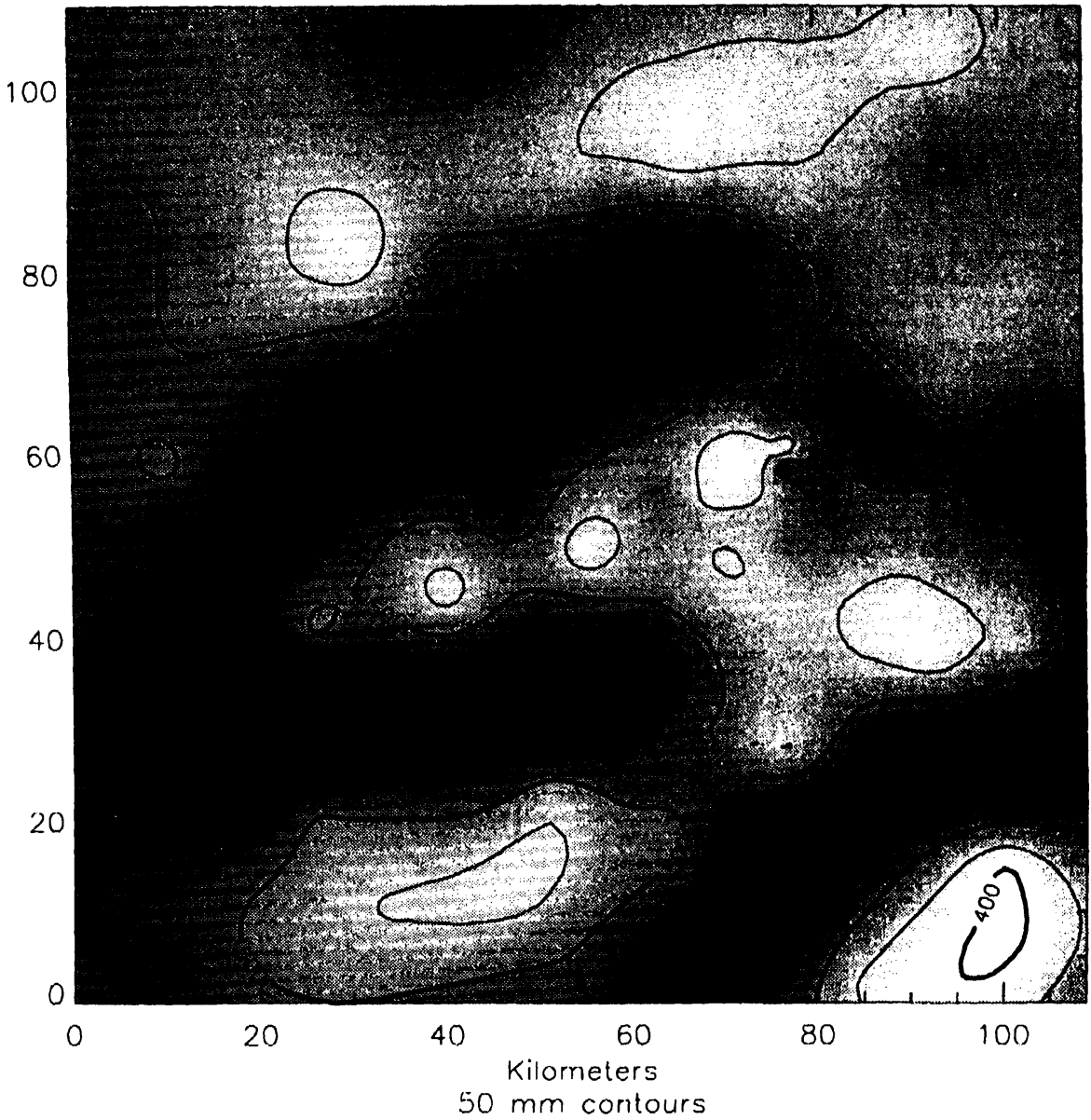

Fig. 4. The spatial variability in rainfall for the wet season of 1992 as shown from measurements from the EPSAT-Niger network (data provided by EPSAT-Niger/ORSTOM. Niamey, Niger)

\subsection{Climatic condition.}

Figure 5 gives an indication of the changing meteorological conditions for the 9-month period, starting in January 1992, incoming solar radiation, minimum, maximum, soil and dew point temperature are shown for the Banizoumbou location at the central-east site. With the migration of the ITCZ southwards, dry north-easterly winds prevail until May. This is shown by the low values of dew point temperature. The nights are generally colder, while during the day the available energy is mainly used to warm up the air to $35-40^{\circ} \mathrm{C}$. A reduction in solar radiation can be observed during January, March and April as a result of an increased aerosol content of the atmosphere. The absence of vegetation leads to the soil being heated up to $50-55 \mathrm{C}$. When the ITCZ shifts to the north in May, southwesterly winds start to prevail. A sudden rise in dewpoint temperature can be observed and the deep humid airmasses favour the formation of cloud, reducing the solar radiation compared to that observed in March. Generally high rates of convection give rise to thunderstorms, which, when organized into systems of squall lines, move in a southwesterly direction. The increased evaporation now gives rise to both lower maximum and soil temperatures than in the dry season.

\subsection{Vegetation}

During the HAPEX-Sahel IOP, the expected gradient in vegetation quantity also occurred over the square. As an example of the type of information collected, Fig. 6 illustrates how the leaf area index (LAI) of the savannah site at the west-central super site changes with time. Similar measurements were taken at all of the other sites and for most vegetation types.

The late arrival of the rains at the central site has led to a late growth of the herbaceous understorey at the savannah site. The grasses, however, continue to grow after the Guiera bushes have reached their maximum leaf area index of 0.35 . By the end of the IOP, the rains have clearly stimulated the growth of the understorey, which reached a peak value of around 1.05. Total maximum leaf area during the IOP at this site was 1.35. At the southern site rains started earlier; consequently vegetation growth began earlier and peaked at a higher level.

\subsection{Soil moisture}

Soil moisture also decreased after the end of the rains. For example, soil moisture in the top $1.5 \mathrm{~m}$ of the profile at 


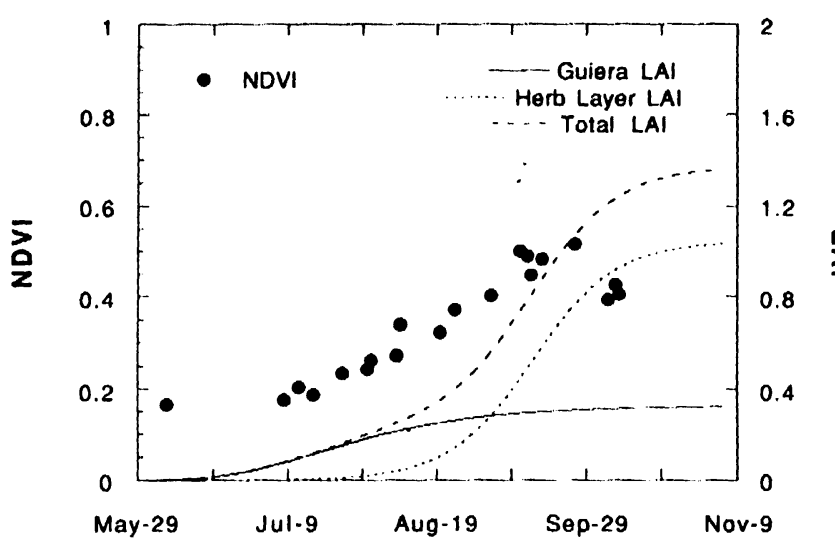

Fig. 6. Leaf area index in 1992 for the fallow savannah site at the West Central Site. Normalized Difference Vegetation Index is also shown (data provided by the University of Maryland, College Park, USA and the University of Arizona, Tucson, USA)

the millet field at the Southern site fell from being close to $120 \mathrm{~mm}$ during the first half of the IOP to $60 \mathrm{~mm}$ at the end. This is shown in Fig. 7, which shows the average soil moisture content in this millet field as measured by neutron probe in 10 tubes. A similar trend in soil moisture depletion was observed at the other sites, after the last rains had stopped. It is also relevant to note that the soil moisture dynamics in the short term heavily influences the runoff and infiltration behaviour of the soils. The low water holding and high infiltration capacity of the soils lead to very short time scales of infiltration; often within 3 or $4 \mathrm{~h}$ after the storm, water had drained through a substantial part of the profile.

\subsection{Surface fluxes}

The main control on the magnitude of the surface fluxes is the availability of soil moisture. During the first half of the IOP, when the soil moisture storage was frequently replenished by rainfall, the energy balance was dominated by evaporative fluxes. Preliminary results indicate that integrated daily Bowen ratios were typically 0.3 for the days immediately after rainfall, but increased slightly as the soil surface dried during following days without rain. Differences in the response of the three vegetation types to drying out after rain are also being inves:' gated. By the end of the IOP, when there had been over 3 weeks without rain, the sensible heat flux had increased to give Bowen ratios of 0.6 at the southern fallow site and 1.0 at the central-east fallow site. Figure 8 shows the trend in Bowen ratio for these sites for the period of dry down after the last rain on 15 September (day number 258).

At a number of sites $\mathrm{CO}_{2}$ flux measurements were made by closed and open path eddy correlation equipment. Figure 9 shows an example from measurements taken at the fallow savannah sub site at the West Central super site by a closed path infrared gas analyzer. On 21 August (Fig. 9a) there is hardly any herbaceous understorey at this site and the fluxes reach a maximum of about $-0.3 \mathrm{mg} \mathrm{m}^{-2} \mathrm{~s}^{-1}$ at

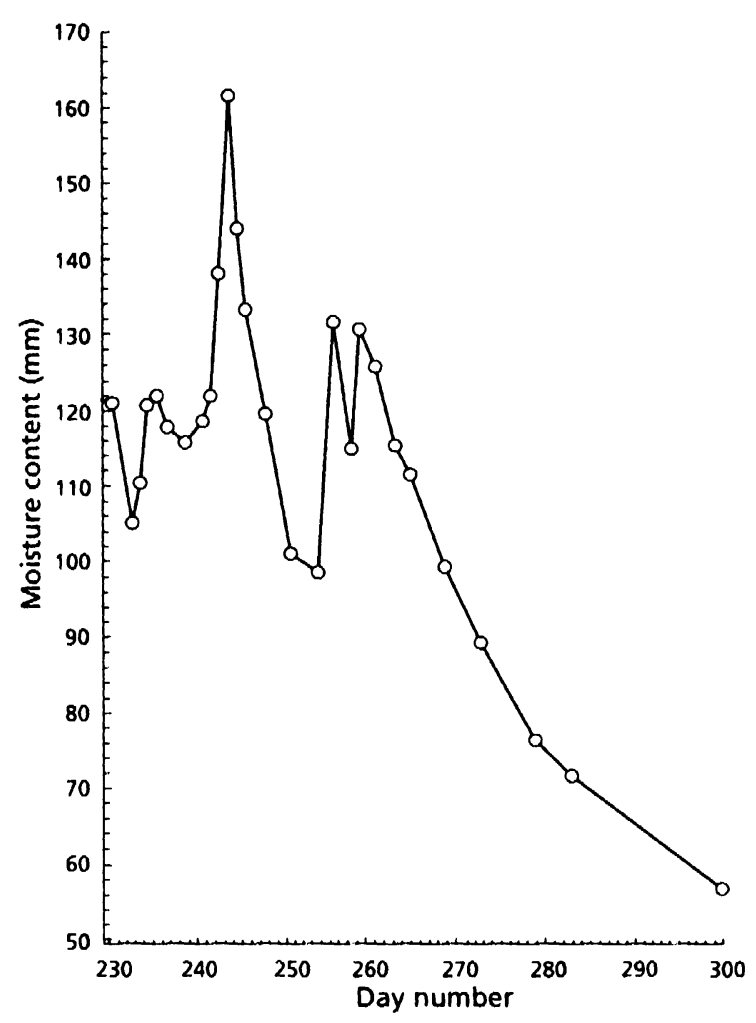

Fig. 7. Soil moisture depletion during the IOP in the 1 op $1.5 \mathrm{~m}$ during the IOP at the millet field at the Southern super-site (data provided by the Institute of Hydrology, Wallingford, UK)

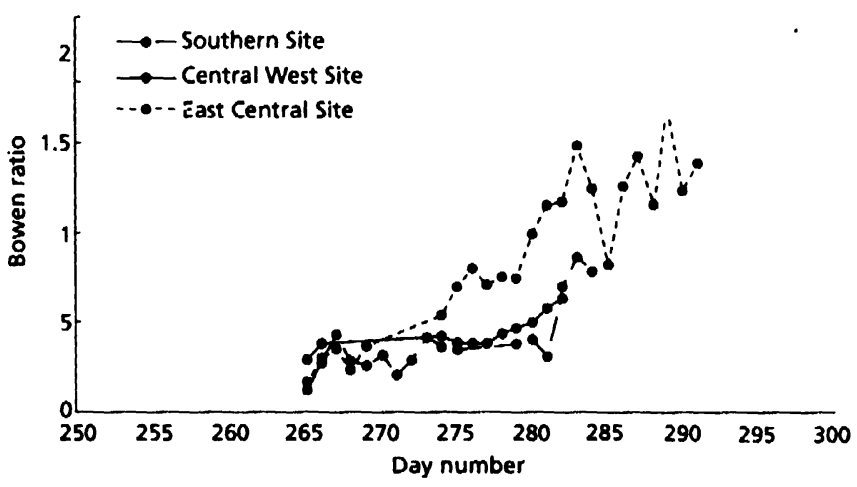

Fig. 8. Bowen ratios during the IOP for the three fallow savannah sites at the three super-sites after the last rains (data provided by the Institute of Hydrology, Wallingford, UK, ORSTOM, Niamey, Niger and the Winand Staring Centre, Wageningen. The Netherlands).

noon. The shape of the curve on this day is almost symmetrical around noon, with the maximum photosynthesis rate extending to about $15.00 \mathrm{hr}$. On 9 October (Fig. 9b) the maximum rate is almost twice as high $\left(0.6 \mathrm{mg} \mathrm{m}^{-2} \mathrm{~s}^{-1}\right)$ because now the understorey has grown and contributes a large part to the flux (see also Fig. 6). Unlike 21 August, the maximum rate of photosynthesis falls down rapidly after about $9.00 \mathrm{~h}$. This indicates early closing of the stomata as a result of environmental stress. 

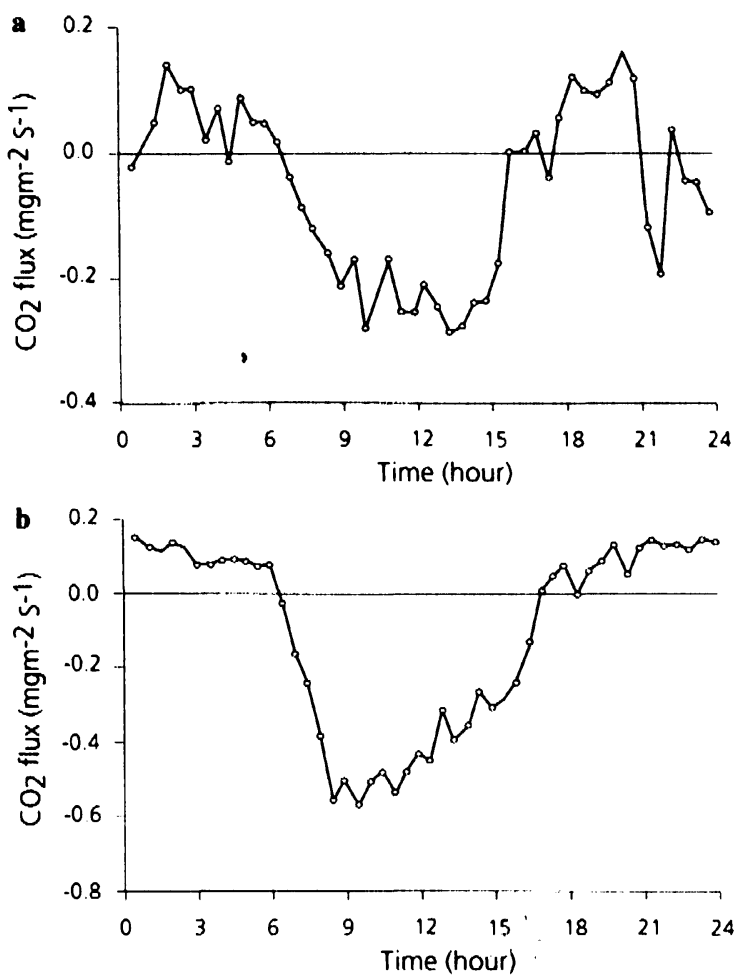

Fig. 9. Measurements al the $\mathrm{CO}_{2}$ flux over the fallow savannah site at the West Central site for 21 August (a) and 9 October (b) (data provided by the Winand Staring Centre, Wageningen, the Netherlands)

\subsection{Boundary layer development}

As a result of the reduction in evaporation and also of the change in atmospheric circulation patterns associated with the southward movement of the ITCZ, the features of the atmospheric boundary layer changed throughout the IOP. Figure 10 shows two examples of potential temperature profiles at the radiosounding station at Hamdallay (see Fig. 1) obtained at the beginning and end of the IOP. A $6^{\circ} \mathrm{C}$ difference is observed in the temperature of the mixed layer. The layer is also considerably drier at the end of the IOP with an average mixing ratio of $6 \mathrm{~g} \mathrm{~kg}^{-1}$ instead of $15 \mathrm{~g} \mathrm{~kg}^{-1}$ at the beginning of the IOP. The mixed layer at 21 August reached a final depth of about $1400 \mathrm{~m}$ and is rather well defined. In contrast on 7 October, at the onset of the dry season, the top of the boundary layer is not well defined. This is generally the case at the end of the IOP when the mixed layer can reach as high as $3000 \mathrm{~m}$. For selected days the boundary layer development has been monitored from a fixed location (Hamdallay) using frequent soundings. Several cases have been found when a large evolution of the boundary layer occurred driven by surface fluxes whereas the free atmosphere above was almost steady state. The spatial variability of the boundary layer dynamics was investigated by launching sondes from a second location: the Southern site, Danguey Gourou or the Dallol Bosso. In this way the reaction of the boundary layer to contrasting surface conditions has been documented. A special 36-h study was conducted to study

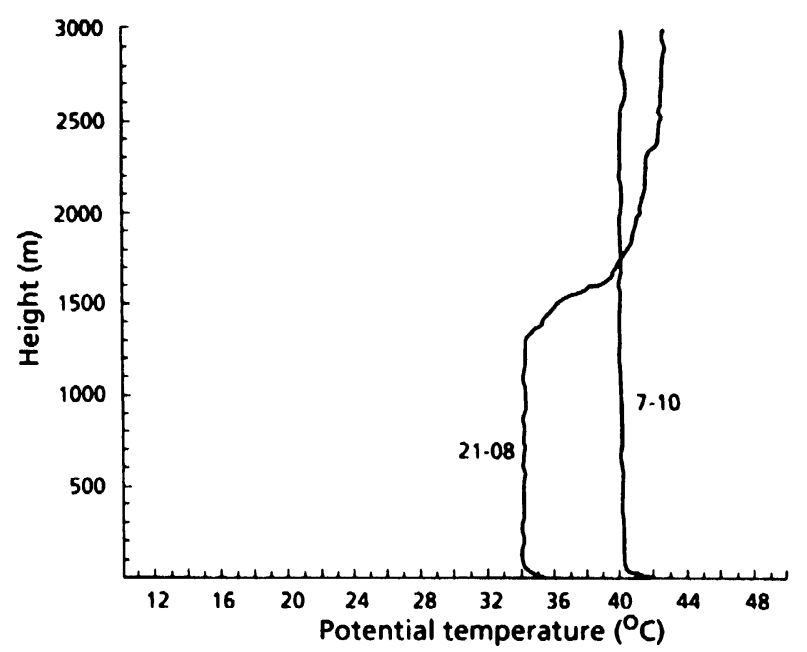

Fig. 10. Radiosonde profiles at the Hamdallay site at the starn (21-(08-92) and end (07-10-92) of the IOP (datta provided by (NRM. Toulousc, France)

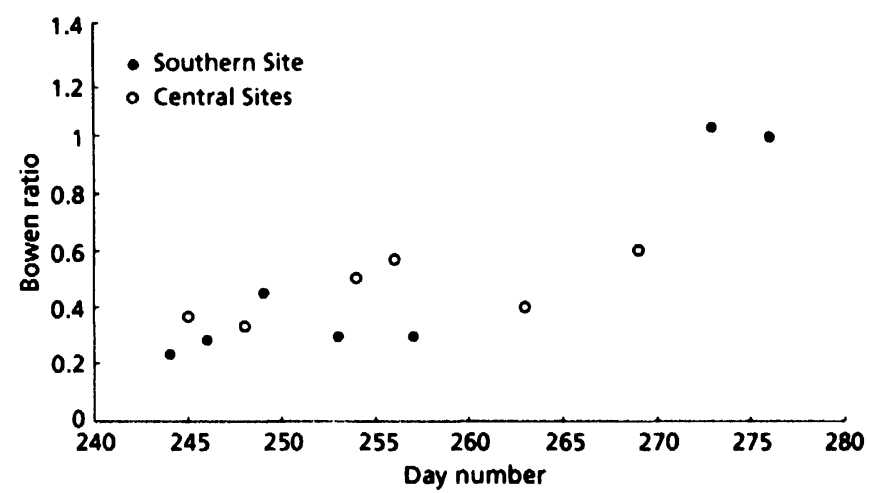

Fig. 11. Bowen ratios obtained from the Merlin flux aircraft for the Central and Southern super-site (data provided by METEO-FRANCE/CNRM/CAM and Laboratoire d'Aerologic. Toulouse, France)

the night time evolution of the boundary layer at both the Hamdallay and Dangue Gourou sites.

A more complete picture of the lower atmosphere can be obtained using data from the flux aircraft which flew long transects at the scale of the square or longer (some transects as long as $150 \mathrm{~km}$; see next section). Flights were coordinated with balloon activities.

\subsection{Remote sensing aircraft and satellite data acquisitions}

Before and during the IOP two types of remotely sensed data were acquired, from satellite and aircraft measurements. During the first 4 weeks the main effort went into acquiring remotely sensed radiometer measurements, while during the last period of the IOP, the emphasis was somewhat more focused on turbulent flux measurements.

Four aircraft were available during the IOP for making measurements from short wave to passive microwave and for making a variety of turbulent flux measurements. 

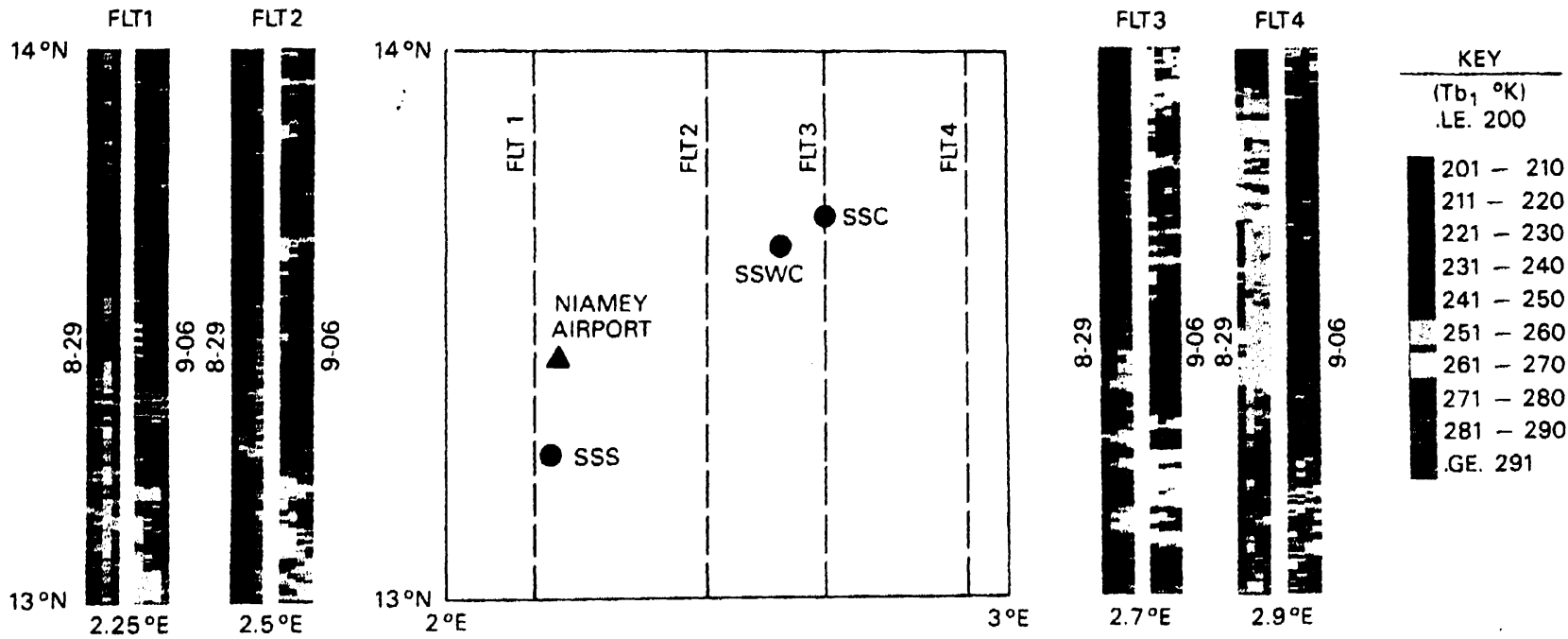

Fig. 12. Push Broom Microwave Radiometer data from the (-130) showing the variability in brightness temperature/soil moisture for a dry (August 29 ) and wet (September 6) day (data provided by NASA/GSFC, Greenbelt, USA)

A Piper Saratoga was equipped with sensors in the visible, near infrared and thermal infrared, having similar characteristics to the ground based sensors. The NASA C-130 carried a Thematic Mapper Simulator, an Airborne Tracking Sun Photometer, an Advanced Solid State Array Spectrometer, a PushBroom Microwave Radiometer, a $37 \mathrm{GHz}$ microwave radiometer, a laser profiler and aerial photography cameras. This set of sensors allowed a large spectral range to be covered. Flight patterns were executed in two typical patterns: detailed coverage of the supersites, and long transects of the $1^{\circ}$ by $1^{\circ}$ square in both optical and microwave mode. The ARAT Fokker 27 operated in two modes: either a remote sensing or a flux measurements mode. In the first mode, executed from 20 August to 18 September it flew POLDER, a visible imager mcasuring polarized reflected radiance from ground and atmosphere at different angles from 0 to $50^{\circ}$ and PORTOS, a five-frequency $(5-90 \mathrm{GHz})$ microwave radiometer, an Integrating Nephetometer to measure aerosol concentration, and several radiation sensors. From 20 September to 9 October the aircraft was equipped with turbulent flux sensors and POLDER and flew in coordination with the Merlin IV. The Merlin IV flux measuring aircraft was equipped to measure the mean atmospheric quantities of the air, as well as the turbulent fluxes of evaporation and sensible heat at several altitudes, and vertical profiles in the atmospheric boundary layer.

The aircraft generally flew in two patterns: a pattern to obtain a detailed coverage of a super site, or transects to gain information about the spatial variability over the square. For each aircraft and measurement purpose these patterns were slightly different. The flights were mostly successful and a good sample of surface evolution was obtained. Figure 11 shows Bowen ratios as measured by the Merlin IV during a number of flights in the IOP. The similarity between the pattern of Bowen-ratio evolution as measured by the ground measuring station (Fig. 7) and the aircraft measurements is good. Another example of the data collected from the aircraft, a Push Broom Microwave image of the $1^{\circ}$ by $1^{\circ}$ square giving the variation in brightness temperature is shown in Fig. 12. The variation in rainfall given in Fig. 4 clearly results in a complementary variation in brightness temperature (i.e. surface soil moisture).

An overview of the satellite imagery which was obtained for the HAPEX-Sahel experiment is given in Table I. The rationale behind the remote sensing programme was to try and acquire all relevant information over a range of spatial and temporal scales, so as to link the local scale surface measurements to the GCM grid box scale. The imagery obtained during this experiment should assist in reaching this goal.

\section{Discussion and Conclusion}

The aim of the experiment was to collect relevant data on a variety of spatial scales which could be used to improve the description of the land-atmosphere interactions in GCMs. As shown in this paper, a large collection of data has indeed been gathered, ranging from soil and vegetation classifications, soil moisture, micrometeorology, $\mathrm{CO}_{2}$, to atmospheric boundary layer data, and aircraft fluxes and remote sensing data. All the data collected during the IOP, plus additional data collected over the whole course of the experiment will be gathered at a central database (HSIS). This database will also contain the relevant satellite imagery. Ultimately, these data will be available in the public domain.

The combination of extensive ground truth data with a large number of aircraft and satellite images will prove to be essential in testing and developing future remote sensing algorithms for semi-arid areas. A variety of upscaling methods will be deployed to achieve the goal of providing realistic inputs to GCMs. 
Table 1. The satellite aquisitions made for the HAPEX-Sahel Database

\begin{tabular}{|c|c|c|c|c|c|}
\hline Satellite sensor & Period & Temp.Resol. & Spatial Resol. & Wavelengths & View angle \\
\hline SPOT & $\begin{array}{l}\text { June-November } \\
24 \text { scenes }\end{array}$ & $\sim 5$ days & $20 \mathrm{~m}$ & Visible near infrared & \pm 27 \\
\hline ERS-1 SAR & (5 scenes) & 35 days & $\sim 20 \mathrm{~m}$ & $5.3 \mathrm{GHZ}$ & 23 \\
\hline LANDSAT TM & $\begin{array}{l}\text { June-November } \\
\text { (9 scenes) }\end{array}$ & 16 days & $30 \mathrm{~m}$ & Visible NIR TIR & $\sim 0$ \\
\hline AVHRR-NOAA 11 & $\begin{array}{c}\text { Júne-November } \\
\text { 1991-1992 }\end{array}$ & 12 hours & $1 \mathrm{~km}$ & VIS NIR, SWIR, TIR & \pm 55 \\
\hline AVHRR-NOAA 12 & $\begin{array}{l}\text { August-October } \\
\text { (morning pass) }\end{array}$ & 24 hours & $1 \mathrm{~km}$ & VIS NIR. SWIR. TIR & \pm 55 \\
\hline METEOSAT & June-November & $1 / 2$ hour & $5 \mathrm{~km}$ & VIS TIR & $\sim 0$ \\
\hline ERS-1 ATSR & August-October & 3 days & $1 \mathrm{~km}$ & SWIR-TIR & 50 \\
\hline ERS-1 WINDSCATT & May-November & 3 days & $50 \mathrm{~km}$ & $5 \mathrm{GH} z$ & $\begin{array}{l}\text { varying } \\
18-50\end{array}$ \\
\hline SSMI & May-November & 2 days & $50 \mathrm{~km}$ & $19.85 \mathrm{GH}$. & 53 \\
\hline
\end{tabular}

An extensive modelling programme is under way to aggregate all the local scale information up to the GCM grid box scale through mesoscale models. This programme which combines state of the art modelling techniques with extensive data requirements, should ultimately enhance the insight of land-atmosphere interactions at the scale of a GCM gridsquare. The results of this modelling effort should then lead to new GCM experiments with more realistic land surface parameterizations.

Acknowledgement. The execution of a collaborative, international experiment such as this requires the dedicated effort of a great many people. many of whom cannot be named here. We wish to thank our collaborators in Niger at DMN. DRE, University of Niamey. INRAN, Mission ORSTOM au Niger, Aéroport de Niamey Authority, Groupement Acrien National, AGRHYMET, ICRISAT and ACMAD. Financial support for HAPEX-Sahel was obtained from ORSTOM, Mćtćo France, INSU/CNRS, Ministère de la Recherche et de l'Espace, Ministère de l'Environment, Minstère de l'Education Nationale et de la Culture, INRA, and the Conseil Régional Midi-Pyrennees (all of France), ODA, NERC, the NERC TIGER programme, JEP (all United Kingdom), NASA (USA), the European Community (grant No. EPOCH-CT90-0024-C. (DSCN) and ENVIRONMENT EV5V-CT91-0033), and from several national funding agencies of Denmark, The Netherlands and Germany.

\section{References}

Adrian, (G. and F. Fiedler, Simulation of unstationary wind and lemperature fields over complex terrain and comparison with observations. Beirr. Phys. Almos., 64, 27-48. 1991.

André, J-C., J-P. Goutorbe, A. Perrier, F. Becker, P. Bessemoulin, P. Bougeault, Y. Brunet, W. Brutsaert, T. Carlson, R. Cuenca, J. Gash, J. Gelpe, P. Hildehrand, P. Lagouarde, C. Lloyd, L. Mahrt, P. Mascart, C. Mazaudier, J. Noilhan, C. Ottle, M. Payen, T. Phulpin, R. Stull, W.J. Shuttleworth, T. Schmugge, (). Taconet, C. Tarrieu, RM. Thepenier, C. Valencogne, D. Vidal-Madjar and A. Weill, Evaporation over land surfaces: first results from HAPEX-MOBIL.HY special observing period. Ann. Geophysicae, 6, 477-492, 1988.

Blyth, E.M., A.J. Dolman and N. Wood, The effective resistance to sensible and latent heat flux in heterogenuous terrain. Q. J. R. Meteorol. Soc., 119, 423-442, 1993.

Bolle, H-J., J-C. André, J.L. Arrue, H.K. Barth, P. Bessemoulin, A. Brasa, H.A.R. de Bruin, G. Dugdale, E.T. Engman, D.I. Evans, R. Fantechi, F. Fiedler, A. van de Griend, A.C. Imeson, A.M. Jochum, P. Kabat, T. Kratzsch, J-P. Lagouarde, I. I anger, R. I Jamas, E. Lopes-Baeza, J. Meli Miralles, L.S. Mubox J. Munniosguren, F. Nerry, J. Noilhan, H.R. Oliver, R. Roth, J. Sanchez Diaz, M. de Santa Alalla, W.J. Shuttleworth, H. Sogaard, H. Stricker, J. Thornes, M. Vauclin, and D. Wickland, EFEDA: European Field Experiment in a Desertification threatened Area. Ann. Geophysicae, 11, 173-189, 1993.

Bougeault, P., B. Bret, P. Lacarère, and J. Noilhan, An experiment with an advanced surface parameterization in a mesobeta-scale model. Part II: The 16 June 1986 simulation. Mon. Weather Rev., 119, 2374-2392, 1991.

Charney, J.G., Dynamics of deserts and drought in the Sahel. Q. J.R. Meteorol. Soc., 101, 193-202, 1975.

Culf, A.D., S.J. Allen, J.H.C. Gash, C.R. Lloyd, and J.S. Wallace, The energy and water budgets of an area of patterned woodland in the Sahel. Agric. For. Meteorol., 66, 65-80, 1993.

Dolman, A.J., A.D. Culf, and C.R. Lloyd, Aerodynamic roughness of an area of natural open forest in the Sahel. Ann. Geophysicae., 10, 930-934, 1993.

Durand, P., J.P. Frangi, and A. Drutlhet, Energy budget for the Sahel surface layer during the ECLATS experiment. Boundary Laver Meteorol., 42, 27-42, 1988.

Folland, C, J. Owen, M.N. Ward, and A. Colman, Prediction of seasonal rainfall in the Sahel region using empirical and dynamical methods. $J$. Forecasting, 10 21-56, 1991.

Frangi, J.P., A. Druilhet, P. Durand, H. Hide, and A. Tinga, Energy budgets of the sahelian surface layer. Ann. Geophysicae., 10, 25-33, 1992.

Gash, J.H.C., J.S. Wallace, C.R. Lloyd, A.J. Dolman, M.V.K. Sivakumar and C. Renard, Measurements of evaporation from fallow Sahe- 
lian savannah at the start of the dry season. Q. J. R. Meteorol. Soc., 117, 749-760, 1991.

Goutorbe, J-P., T. Lebel, A. Tinga, A.J. Dolman, E.T. Engman, J.H.C. Gash, P. Kabat, Y.H. Kerr, B. Monteny, S. Prince, P. Sellers, J.S. Wallace and M. Hoepfiner, Experiment plan for HAPEX-Sahel. ORSTOM, Montpellier. 1992.

Laval, K. and L. Picon, Effect of a change of surface albedo of the sahel on climate. J. Atmos. Sci., 43, 2418-2429, 1986.

Lebel, T., H comme HAPEX. Hydrologic Hors Bassin Versant. In Le Transfert d'échelle. Proc. 4th Sfminaire Informatique ORSTOM. C.Mullon (ed.), pp 493-506, ORSTOM Editions (Collections Colloques et Séminaires). Paris, 1990.

Lebel, T., H. Sauvageot, M. Hoepfrner, M. Desbois, B. Guillot, and P. Hubert, Rainfall estimation in the Sahel, the EPSAT-NIGER experiment. Hydrol. Sci. J., 37, 201-215, 1992.

Nicholson, S.E., Long term changes in African rainfall. Weather, 44, 46. 64. 1989.

Noilhan, J. and P. Lacarrère, GCM gridscale evaporation from mesoscale modelling. ECMWF Proceedings, 16-18 September 1991. Reading. UK. pp. 245-274, 1993.
Rowntree, P.R.. Review of general circulation models as a basis for predicting the effects of vegetation change on climate. In Forests. Climute' and Hydroleg!: Re'gional Impacts, Eds. E.R.C. Evans and F.B. Thompson. United Nations University, Singapore. pp. 162-196, 1988.

Sellers, P., F.(. Hall, G. Asrar, D.E. Strebel and R.F. Murphy, An overvicw of the First International Satellite Land Surface Climatology Project (ISLSCP) Ficld Experiment (FIFF). J. Geophy.s. Re's., 97 D17. 18.345-1837.3, 1992

Shuttleworth, W.J., Insight from lange-scale observational studies of land/atmosphere interactions. Surn: Geophys., 12, 3-30. 1991.

Taupin, J.D., A. Amani, and T. Lebel, Small scale variability of the annual rainfall in the Sahcl. In Exchunge processe's at the land surface for a range' of space and time scale's, Eds. Bolle. H-J., J. Kalma, and R.A. Feddes. Proceedings of the Yokohama Symposium, IAHS. Wallingford. Publ. no. 212. pp 593-6(1)2. 1993. 